\title{
Detection and Quantification of Botrytis cinerea by ELISA in Pear Stems During Cold Storage
}

\author{
U. M. Meyer and R. A. Spotts, Mid-Columbia Agricultural Research and Extension Center, Oregon State Univer- \\ sity, Hood River 97031; and F. M. Dewey, Department of Plant Sciences, University of Oxford, South Parks Road, \\ Oxford OX1 3RB, UK
}

\begin{abstract}
Meyer, U. M., Spotts, R. A., and Dewey, F. M. 2000. Detection and quantification of Botrytis cinerea by ELISA in pear stems during cold storage. Plant Dis. 84:1099-1103.

Botrytis cinerea was detected and quantified in pear stems from six orchards in the Pacific Northwest, and changes in fungal biomass in the stems after 6 and 8 months of cold storage in regular (air) atmosphere were studied. The fungus was detected by plating stem halves on selective medium and by enzyme-linked immunosorbent assay (ELISA) using the Botrytis-specific monoclonal antibody BC-12.CA4. Both methods demonstrated that the incidence of $B$. cinerea increased from 6 to 8 months, but ELISA was more sensitive than standard isolation. Quantitative ELISAs on stems indicated that over $200 \mu \mathrm{g}$ of $B$. cinerea biomass per gram of stem tissue was present in the stems of visibly rotted fruits, but usually less than $35 \mu \mathrm{g} / \mathrm{g}$ was present in stems from fruits without visible gray mold. Aureobasidium pullulans, Penicillium spp., Alternaria spp., and Cladosporium spp. were commonly isolated from stem tissue. A. pullulans was present in $86 \%$ of the stems from which $B$. cinerea was detected. Use of the monoclonal antibody BC-12.CA4 could help in determining the infection path of B. cinerea in pear stems and detection of latent infections, enabling the timing and method of control of stem end rot to be optimized.
\end{abstract}

Additional keyword: antagonism

Postharvest decay during cold storage causes serious losses each year to Pacific Northwest pears. Stem end rot on pears, Pyrus communis L., is caused by Botrytis cinerea Pers. and has increased in importance as a postharvest disease. $B$. cinerea was responsible for $54 \%$ of all decay of Anjou pears in the years 1994 through 1996 , with 26,20 , and $8 \%$ originating at punctures, stem ends, and calyx ends, respectively (14). Infection of the stem end may start with contamination of the abscission zone by spores of $B$. cinerea that are present in the orchard, in dump tanks, or in packinghouses and storage rooms (14).

Detection and quantification of specific fungi in plant tissues in the presence of other fungi are difficult. Classical methods such as isolation on selective media are useful but subject to limitations, i.e., many pathogens are masked by overgrowth of faster growing fungi. Quantitative nucleic acid-based methods have been developed $(9,20,23)$, but these methods are expensive and not easy to perform routinely. Other methods include measurement of glucu-

Corresponding author: Robert A Spotts

E-mail: robert.spotts@orst.edu

Accepted for publication 21 June 2000.

Publication no. D-2000-0724-01R

(C) 2000 The American Phytopathological Society ronidase activity, but this method is limited to studies using GUS transformants (21). Immunological methods provide a promising alternative. Dewey et al. (5), Bermingham et al. $(1,2)$ and KarpovichTate et al. (12) have shown that specific fungi can be detected and their biomasses in plant tissues estimated by using monoclonal antibodies. Several researchers have raised both polyclonal and monoclonal antibodies to $B$. cinerea, but none are widely used in quantitative assays $(3,16,22,24)$. In a recent study, Meyer and Dewey produced a Botrytis-specific monoclonal antibody, BC-12.CA4 (19), that was useful in the detection and quantification of $B$. cinerea in juice from grapes for wine production (4). BC-12.CA4 recognizes an antigen, possibly a glycoprotein, with the antigenic binding site on L-rhamnose. The antigen is expressed from the first appearance of the germ tube during germination and can be observed by immunofluorescence along the entire length and tip of the germ tube but not on conidia (U. M. Meyer, unpublished). The antigen is produced by fungi belonging to the genus Botrytis (19). The specificity of BC12.CA4 has been determined by enzymelinked immunosorbent assay (ELISA) against cell-free surface washings of cultured isolates of a range of fungi (19).

The purpose of this study was to develop an immunological method to detect $B$. cinerea in the stem tissue of pears during cold storage and to determine infection levels in stems before development of visible symptoms of stem end rot in pear fruit. We used the monoclonal antibody BC-12.CA4 and isolation techniques for detection and quantification of $B$. cinerea in pear stems.

\section{MATERIALS AND METHODS}

Collection and storage of pears. Anjou pears were harvested by hand at commercial maturity in September 1998 from two orchards in the Hood River Valley, OR, and four orchards in the Mount Adams, WA, pear growing districts. In each orchard, 10 trees were arbitrarily selected, and two boxes of fruit $(20 \mathrm{~kg}$ of fruit per box) were harvested from each tree. Pears were packed in wooden boxes lined with perforated polyethylene bags and placed in cold storage in regular atmosphere at $-1^{\circ} \mathrm{C}$.

Pear stem assay. After 6 and 8 months of storage, one of the 20 boxes from each orchard was randomly selected, and 50 pears were removed for stem assays. The pears had no visible decay of the cortical tissue. Stems were removed from pears with a metal spatula. Stem surfaces were disinfested for $30 \mathrm{~s}$ in $70 \%$ ethanol, placed in sterile distilled water for $1 \mathrm{~min}$, then dried aseptically for $5 \mathrm{~min}$ on sterile filter paper. All stems were cut in half lengthwise with a scalpel under aseptic conditions. One stem half was placed on prune lactose yeast agar (17), and plates were incubated at $21 \pm 2^{\circ} \mathrm{C}$. Presence of fungal growth was evaluated after 7 to 10 days. Prune lactose yeast agar contains tannins and a high sugar content. Botrytis grows and sporulates rapidly on this medium, making it easy to identify among the other fungi growing from the pear stem. The other stem half was tested by a modification of the ELISA method of Bossi and Dewey (3), as described below. After 8 months of storage, stems on pears that had visible stem end decay of cortical tissue also were removed from 10 to 20 randomly selected fruits per orchard and processed as described above.

ELISA method. Each stem half was weighed and placed in a $1.5-\mathrm{ml}$ Eppendorf tube. One milliliter of phosphate buffered saline (PBS: $0.8 \% \mathrm{NaCl}, 0.02 \% \mathrm{KCl}$, $0.02 \% \mathrm{KH}_{2} \mathrm{PO}_{4}$, and $0.115 \% \mathrm{Na}_{2} \mathrm{HPO}_{4} ; \mathrm{pH}$ 7.2) was added to each sample, and stems were macerated with a metal spatula. All samples were vortexed and held at $21 \pm$ 
$2^{\circ} \mathrm{C}$ for $1 \mathrm{~h}$ to allow antigens to diffuse into the buffer. Samples were centrifuged at $12,000 \times g$ for $3 \mathrm{~min}$, and the supernatant was used to coat microtiter wells (Labsystems, 9502037, Helsinki, Finland). Fifty microliters was added to each well, and three replicate wells were used for each half-stem sample. Samples were held overnight at $4^{\circ} \mathrm{C}$, and then the wells were washed three times with PBS. The working volume of all solutions was $50 \mu \mathrm{l}$ in all following steps except for the blocking step, which was $200 \mu \mathrm{l}$. Wells were blocked for 30 min with a solution containing $0.3 \%$ casein $(\mathrm{wt} / \mathrm{vol})$ and $0.02 \%$ sodium azide (wt/vol) in PBS, then incubated $1 \mathrm{~h}$ with the murine monoclonal antibody (MAb) BC-12.CA4. Afterward, wells were incubated another hour with a commercial anti-mouse IgG alkaline phosphatase conjugated antibody (A5324, Sigma Chemical Co., St. Louis, MO) diluted 1:1,000 in PBST (PBS with $0.05 \%$ Tween 20). Between each single step, wells were washed four times with PBST. Wells were incubated with the substrate $p$ nitrophenyl phosphatase in diethanolamine buffer (27) for $30 \mathrm{~min}$ or until color reaction was visible (3 to $20 \mathrm{~h}$ ). Absorbance values were determined with an automated microplate reader (Bio-Tek EL309, BioTek Instruments, Winooski, UT) at 405 nm.

Preparation of freeze-dried mycelium for quantifying ELISA reactions. A stock of freeze-dried powdered mycelium of $B$. cinerea isolate P-6g (3) was used to pre- pare a dilution series of reference antigens. The mycelium was grown on grape juice in 250-ml conical flasks. Grapes (Vitis vinifera cv. Thompson Seedless) were squashed in a garlic press. The juice was filtered through a double layer of muslin, $50 \mathrm{ml}$ was added to each flask, and flasks were autoclaved at $121^{\circ} \mathrm{C}$ for $20 \mathrm{~min}$. After cooling, three 3-mm plugs from the leading edge of a 10-day-old culture were added to each flask, and flasks were placed at $21 \pm$ $2^{\circ} \mathrm{C}$ for 12 days. Mycelial mats were removed, snap frozen in liquid nitrogen, blended in a Waring blender, and freezedried to obtain a fine powder, which was stored at $-20^{\circ} \mathrm{C}$. To prepare the dilution series of reference antigens, freeze-dried mycelium $(1 \mathrm{mg} / \mathrm{ml})$ was suspended in PBS. The suspension was vortexed for 1 min, held for $60 \mathrm{~min}$, then centrifuged 3 $\min$ at $12,000 \times g$. The cell-free supernatant was diluted serially with PBS to get a range from $1 \mathrm{mg}$ to $1 \mu \mathrm{g}$ per $\mathrm{ml}$ and used to coat triplicate microtiter wells. PBS only was added to control wells. Wells were incubated overnight at $4^{\circ} \mathrm{C}$ and processed by ELISA as described in the pear stem assay above.

Method for estimating biomass of $B$. cinerea in pear stems. The results from the dilution series of reference antigens were used to make a standard calibration curve, with absorbance values in each assay being proportional to the concentration of antigens over the range of $1 \mathrm{mg}$ to $1 \mu \mathrm{g}$ per $\mathrm{ml}$ of buffer (Fig. 1A). The lower range of the curve was linear, and a regression

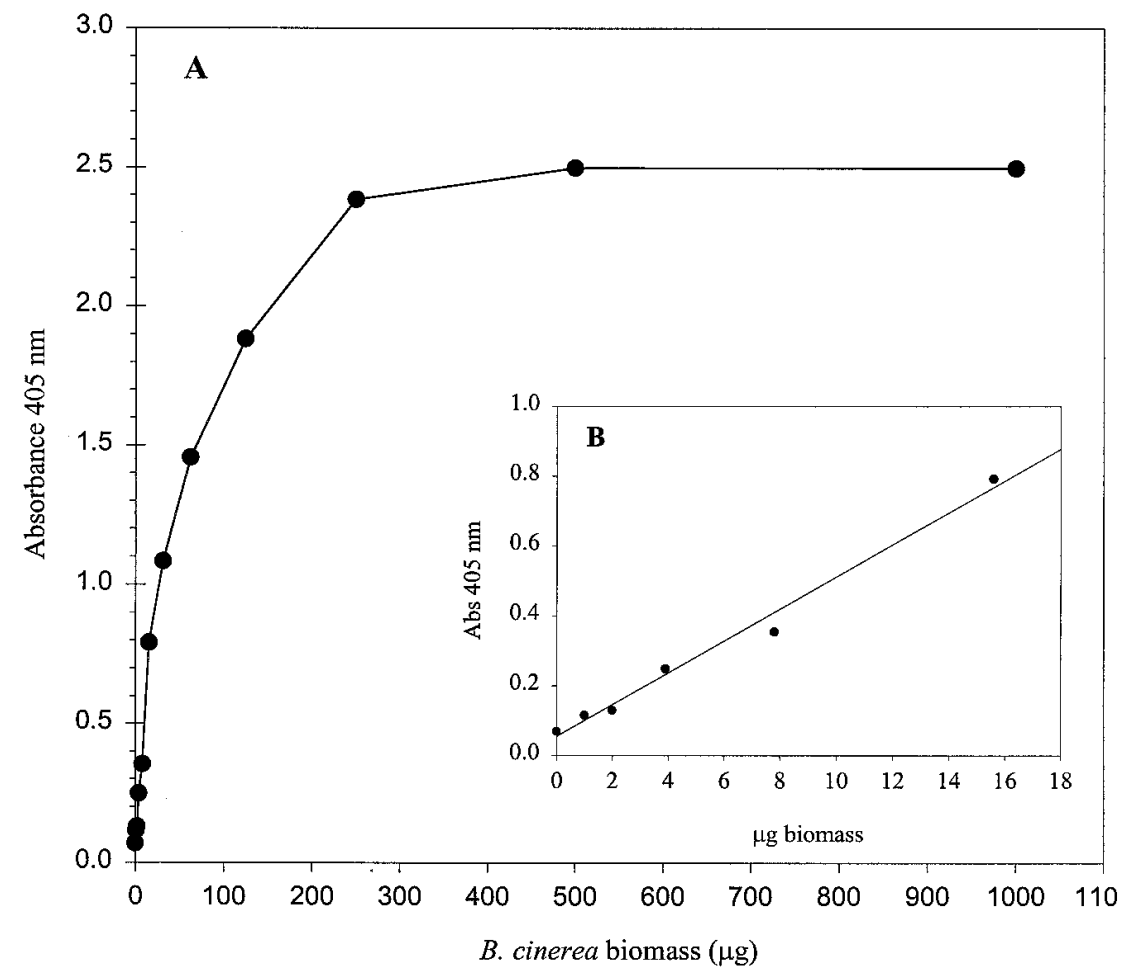

Fig. 1. (A) Standard calibration curve with the concentration of Botrytis cinerea isolate P-6g biomass $(\mu \mathrm{g})$ proportional to the absorbance values at $405 \mathrm{~nm}$ over the range of $1 \mu \mathrm{g}$ to $1 \mathrm{mg} / \mathrm{ml}$. (B) Linear regression line for lower linear values (e.g., 1 to $18 \mu \mathrm{g}$ biomass). line was made (Fig. 1B). It was necessary to make a calibration curve for each assay because the absorbance values varied from day to day. The biomass of $B$. cinerea in pear stems was estimated by inverse prediction from the calibration curve. The mean absorbance of the three replicates per stem was used to estimate the corresponding biomass. To compare the fungal biomass values in stem tissues, biomass was calculated as micrograms of fungal mass per gram of stem tissue.

Ten stems from different orchards where no fungal growth was observed on one stem half were used as controls in the ELISA for determining the background absorbance. The absorbance values did not differ from those obtained with PBS. Some stem tissues from immature fruits reacted directly with both peroxidase and phosphatase substrates, indicating the presence of these enzymes in the stem tissue (U. M. Meyer and R. A. Spotts, unpublished). Boiling the samples in the buffer for $5 \mathrm{~min}$ can eliminate enzyme interference. However, in the studies reported herein with stems from mature stored fruits where no fungal growth was detected on agar plates or by ELISA, no reaction from the plant tissue with the substrate was observed.

Test of MAb BC-12.CA4 for cross-reaction with fungi isolated from pear stems. A variety of fungi were isolated from pear stems, mainly from those stems where half of the stem gave a positive result for the presence of Botrytis when tested by ELISA. Single spore cultures were incubated on PDA (39 g/liter) (Difco Laboratories, Detroit, MI) for 7 to 10 days at $21 \pm 2{ }^{\circ} \mathrm{C}$. Water-soluble surface antigens were removed from plate cultures by flooding plates with $5 \mathrm{ml}$ of PBS, then stroking a pipette tip over the surface. Washings were transferred to $1.5-\mathrm{ml} \mathrm{Ep}$ pendorf tubes and centrifuged to remove particulate materials. The supernatant was diluted 1:5 with PBS and used to coat microtiter wells in triplicate, $50 \mu$ per well. Wells were incubated overnight at $4{ }^{\circ} \mathrm{C}$ and processed by ELISA as described in the pear stem assay, except that the secondary antibody was replaced with an anti-mouse peroxidase conjugate (Sigma A0412) diluted 1:1,000 in PBST, and tetramethyl benzidene was used as the substrate as described by Bossi and Dewey (3). Absorbance was read at $450 \mathrm{~nm}$.

\section{RESULTS}

In general, there was some agreement between the two methods of assessing $B$. cinerea in pear stems. After 6 months of storage, the percentage of stems with $B$. cinerea infections was low with both methods; and an increase was detected by both methods after 8 months of storage. However, B. cinerea was detected more frequently by the ELISA method than by isolation. B. cinerea was detected in 10.6 and $57 \%$ of the stems with the ELISA 
technique and in 0.7 and $6 \%$ by isolation after 6 and 8 months, respectively.

There was a clear increase in the percentage of pear stems in which $B$. cinerea was detected in all six orchards between 6 and 8 months in cold storage (Fig. 2). After 6 months of storage, infected stems ranged from 2 to $24 \%$, increasing to 8 to $94 \%$ after 8 months. In orchards I and II, where the lowest percent stem infections were found (Fig. 2), biomass estimates increased from $5.8 \mu \mathrm{g}$ and $13 \mu \mathrm{g}$ after 6 months to $75 \mu \mathrm{g}$ and $124 \mu \mathrm{g}$ per gram fresh weight of stem tissue after 8 months storage for orchards I and II, respectively (Table 1). These biomass estimates overlapped with the biomass of $B$. cinerea found in stems where visible rot was detected. In orchards III to VI, ELISAs indicated the presence of $B$. cinerea in a high percentage of stems after 8 months (Fig. 2), but the biomass levels were significantly less than levels found in stems where disease occurred in cortical tissues (Table 1). The biomass levels in stems from fruit with visible stem end rot varied among the orchards (Table 1). Mean levels were 255 and $214 \mu$ g of biomass per gram of stem tissue in orchard I and IV, respectively, and between 306 and $441 \mu \mathrm{g}$ of biomass per gram of stem tissue in the other orchards. In orchard II, levels up to $395 \mu \mathrm{g}$ of biomass per gram of stem tissue were detected in fruit without symptoms. Absorbance values were in the linear range of the curve, and high biomass values were the result of calculations converting absorbance to micrograms of biomass per gram of stem tissue.

Fungi isolated from pear stems on agar mainly belonged to five genera, Aureobasidium pullulans, Penicillium spp., Alternaria spp., Cladosporium spp., and $B$. cinerea. Aureobasidium was the most frequently detected fungus on the agar plates from all six orchards (Fig. 3). The mean incidence of detection was 61.3 and $60.6 \%$ after 6 and 8 months storage, respectively, and ranged from 34 to $76 \%$ in individual orchards. Mean incidence of detection of A. pullulans in stems in which $B$. cinerea was detected by ELISA was $81.6 \%$ (ranging from 66 to 100\%) after 6 months and $59.8 \%$ (ranging from 25 to $85 \%$ ) after 8 months (Fig 3B).

A total of 100 stems were tested from fruit where stem end rot occurred in cortical tissue. In $9 \%$ of the samples, B. cinerea was not detected by ELISA or isolated on agar. Fungi present in these stems were $A$. pullulans, Alternaria spp. or Penicillium spp., suggesting that they may be causing the stem end rot in these cases. In the rest of the stems, $B$. cinerea was detected by both ELISA and isolation on agar.

Tests of the monoclonal antibody BC12.CA4 with the fungi frequently isolated from pear stems resulted in no cross-reactions, indicating that the antibody was specific to $B$. cinerea. A selection of the fungi tested is presented in Figure 4. $B$. cinerea 62 is from the collection at MCAREC in Hood River.

\section{DISCUSSION}

We have shown that the ELISA method, employing the MAb specific for $B$. cinerea, BC-12.CA4, developed by Meyer and Dewey (19), can be used to detect and quantify $B$. cinerea in the stem end of pears in storage before visual decay symptoms are apparent. B. cinerea was detected more frequently by ELISA than by isolation on agar. Several factors may account for the differences between the two methods. The MAb BC-12.CA4 does not distinguish between viable and dead mycelia. If $B$. cinerea is nonviable as a result of interactions with other microbes or unfavorable environmental conditions, the antigens still may be present and will be detected by BC-12.CA4. A number of microorganisms are known to antagonize Botrytis. Of the fungi we frequently found in the stems, A. pullulans is a fungal antagonist $(13,15,18)$. Penicillium chryso- genum can inhibit germination of Botrytis fabae (10) and has been found in dump tank water and pear fruit lesions in the Mid-Columbia region of Oregon and Washington (25). Competition for nutrients is important in systems where biocontrol is involved (8). In pear stem tissue of fruit in cold storage, where the presence of nutrients is limited, fungi with nutrient requirements simpler than $B$. cinerea may have an advantage. $B$. cinerea requires nutrients for a successful infection (6), and it is possible that the availability of nutrients diminishes during storage as the stem tissue dries out.

B. cinerea often was detected by ELISA in one stem half but was not isolated from the other half. Differences in fungal presence in the two stem halves could be due to uneven colonization of the stem tissue. In addition, the first fungi to grow from stems plated on agar were frequently Aureobasidium and Alternaria, and it is possible that they either overgrow and mask other fungi such as $B$. cinerea or antagonize

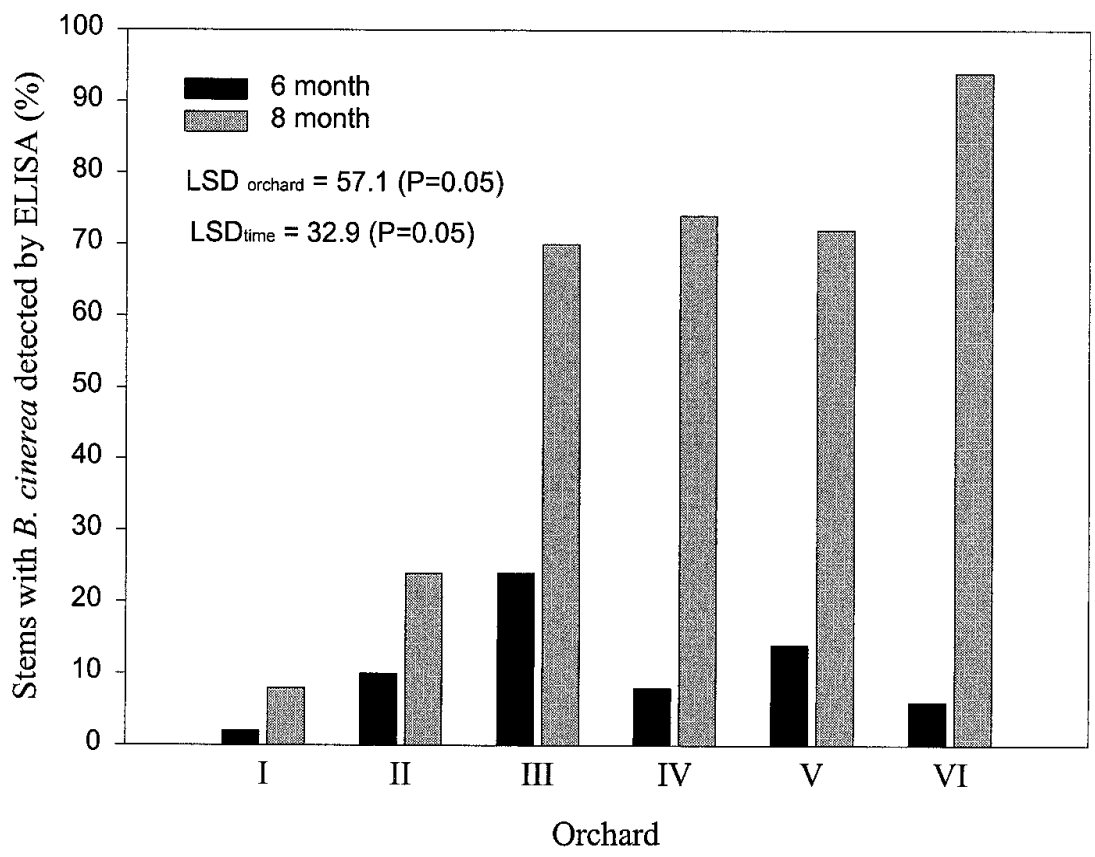

Fig. 2. Percentage of pear stems in which Botrytis cinerea was detected by enzyme-linked immunosorbent assay (ELISA) after 6 and 8 months of cold storage. Pears were collected from six independent orchards. Fifty stems per orchard were evaluated at each sampling time.

Table 1. Biomass of Botrytis cinerea in enzyme-linked immunosorbent assay (ELISA)-positive pear stems from six orchards after 6 and 8 months of cold storage

\begin{tabular}{|c|c|c|c|}
\hline \multirow[b]{3}{*}{ Orchard } & \multicolumn{3}{|c|}{ B. cinerea biomass in stem $(\mu \mathrm{g} / \mathrm{g})^{\mathbf{a}}$} \\
\hline & \multicolumn{2}{|c|}{ No visible fruit rot } & \multirow{2}{*}{$\frac{\text { Visible fruit rot }}{8 \mathrm{mo} .}$} \\
\hline & $6 \mathrm{mo.}$ & $8 \mathrm{mo.}$ & \\
\hline I & $5.8 \pm 0.0$ & $74.9 \pm 18.3$ & $254.6 \pm 105.9$ \\
\hline II & $13.0 \pm 2.5$ & $124.3 \pm 43.3$ & $381.7 \pm 69.6$ \\
\hline III & $1.4 \pm 0.4$ & $7.9 \pm 0.9$ & $440.7 \pm 90.1$ \\
\hline IV & $3.5 \pm 0.0$ & $4.9 \pm 0.3$ & $213.7 \pm 35.9$ \\
\hline V & $3.9 \pm 1.8$ & $3.1 \pm 0.3$ & $338.9 \pm 47.5$ \\
\hline VI & $34.7 \pm 12.1$ & $7.3 \pm 1.2$ & $306.4 \pm 31.3$ \\
\hline
\end{tabular}

${ }^{\mathrm{a}}$ Mean \pm standard error. 
them by nutrient competition on the agar. It is evident that the ELISA technique has a much higher sensitivity in detecting $B$. cinerea in stem tissue than the plating technique.

Comparison of the fungal biomass in stems from pears by ELISA, with or without visible stem end rot, indicates that a critical biomass may be needed in the stems before stem end rot develops. In orchards I and II after 8 months storage, we found fewer stems with $B$. cinerea, but those that were infected had a higher biomass level ( 75 and $124 \mu \mathrm{g}$ per gram of stem tissue) than stems from the other orchards. This suggests that fungal growth in pear stems in orchards I and II had reached a development stage close to a level (over about $200 \mu \mathrm{g}$ per gram of stem tissue) where disease symptoms are initiated in the fruit tissue. In orchards III to VI, the number of stems with detectable levels of $B$. cinerea increased between 6 and 8 months of storage, but because the biomass levels were much lower (less than $8 \mu \mathrm{g} / \mathrm{g}$ at 8 months) than those found in stems where stem end rot had developed, we consider it unlikely that stem end rot would develop from those stems. A latent or quiescent phase of $B$. cinerea is common in many crops $(7,11)$, and it is likely that the latent infections become active when host defenses diminish during storage.

It is possible that $B$. cinerea penetrates the stem tissue either directly or through wound sites. At June drop, many unfertile fruit drop and leave wounds for fungal penetration in the fruit cluster. The abscission zone that is exposed on the stems at harvest provides an additional wound site for pathogens. This latter wound does not heal, even after 6 months in storage, and can be colonized by $B$. cinerea (26). Further studies during the growing season and harvest will help determine the infection path of $B$. cinerea in pear stems. Especially of interest is whether infections occur through the abscission zone during harvest and storage or by penetration of the stem surface during the growing season. The monoclonal antibody BC-12.CA4 in conjunction with immunofluorescent light microscopy and/or immunocytochemical techniques for TEM could aide in these investigations and even enable detection of latent infections because of its high level of sensitivity and specificity. Such quantitative information will help determine the optimum timing and method for control of stem end rot of pear caused by $B$. cinerea.

\section{ACKNOWLEDGMENTS}

Alternaria spp. and Cladosporium spp. in the 900000 series were kindly provided by Rodney Roberts, USDA/ARS, TFRL, Wenatchee, WA. This project was supported in part by the Winter Pear Control Committee. Use of trade names in this article does not imply endorsement by Oregon State University of the products named or criticism of similar products not mentioned. Oregon Agricultural Experiment Station Technical Paper 11587.
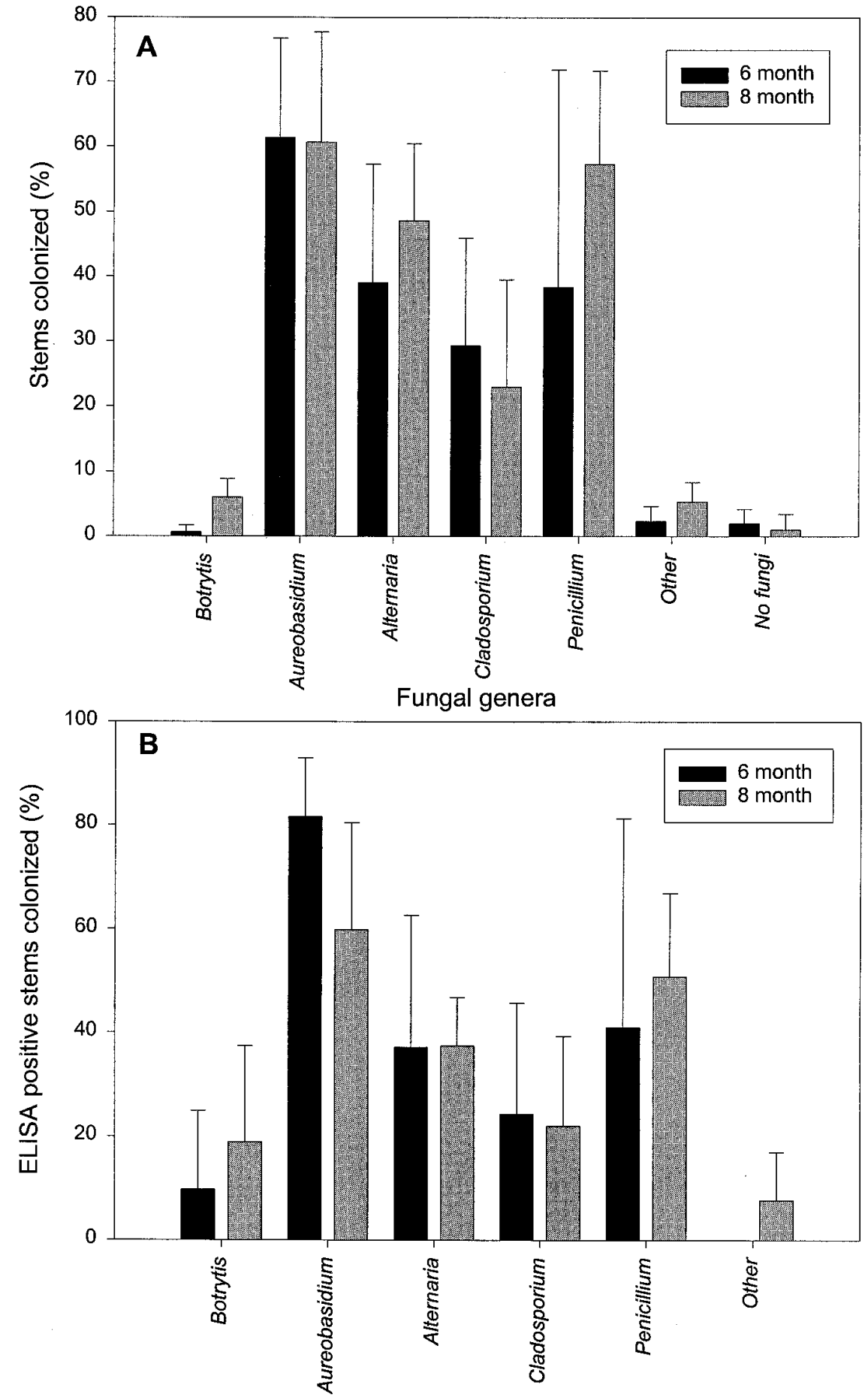

Fungal genera

Fig. 3. (A) Percentage of halved stems with fungal growth on prune lactose yeast agar from 50 pear stems from each of six orchards and (B) percentage of halved stems with fungal growth in which Botrytis cinerea was detected by enzyme-linked immunosorbent assay (ELISA) in the corresponding stem half. Pears were tested after 6 and 8 months of storage. Bars are standard deviations of the means for the six orchards.

\section{LITERATURE CITED}

1. Bermingham, S., Dewey, F. M., and Maltby, L. 1995. Development of a monoclonal antibody-based immunoassay for the detection and quantification of Anguillospora longissima colonizing leaf material. Appl. Environ. Microbiol. 61:2606-2613.

2. Bermingham, S., Maltby, L., and Dewey, F. M. 1996. Monoclonal antibodies as tools to quantify mycelium of aquatic hyphomycetes.
New Phytol. 132:593-601.

3. Bossi, R., and Dewey, F. M. 1992. Development of a monoclonal antibody-based immunodetection assay for Botrytis cinerea. Plant Pathol. 41:472-482.

4. Dewey, F. M., Ebeler, S. E., Adams, D. O., Noble, A. C., and Meyer, U. M. Quantification of Botrytis in grape juice determined by a monoclonal antibody-based immunoassay. Am. J. Enol. Vitic. In press. 


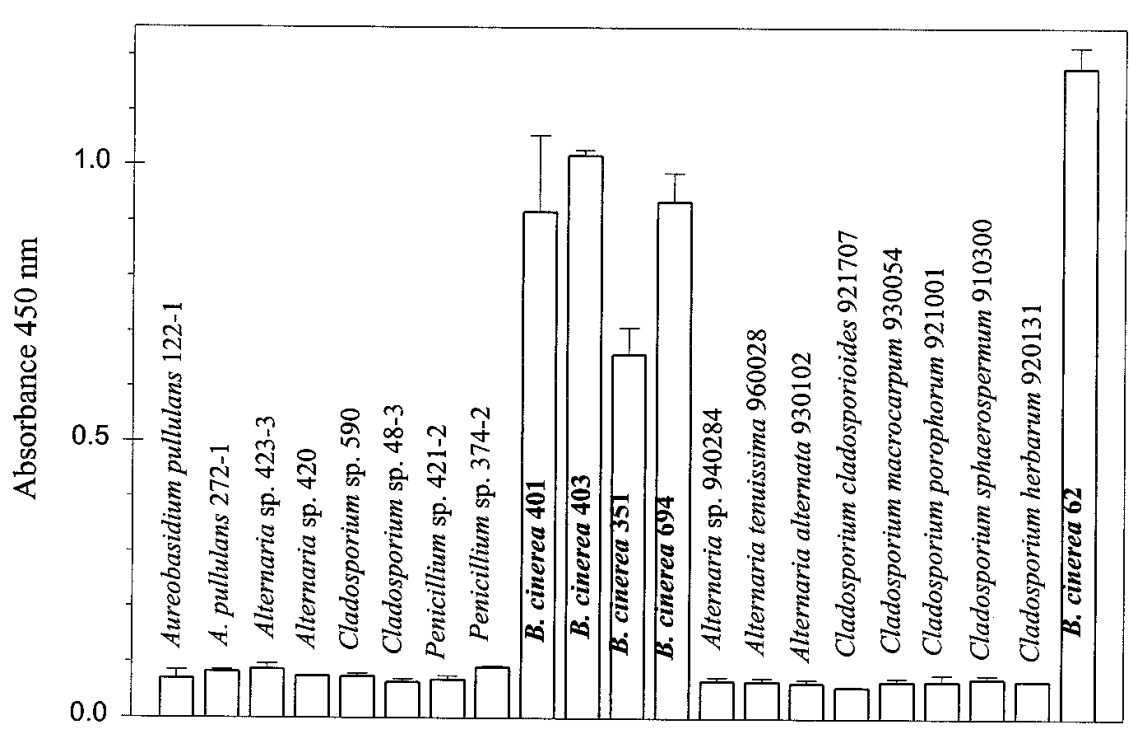

Fungal isolates

Fig. 4. Test of the monoclonal antibody BC-12.CA4 for cross-reaction with fungi isolated from pear stems. Bars are standard deviations of the means of three replicates.

5. Dewey, F. M., Twiddy, D. R., Phillips, S. I., Grose, M. J., and Wareing, P. W. 1992. Development of a quantitative monoclonal antibody-based immunoassay for Humicola lanuginosa on rice grains and comparison with conventional assays. Food Agric. Immunol. 4:153-167.

6. Edlich, W., Lorenz, G., Lyr, H., Nega, E., and Pommer, E. H. 1989. New aspects on the infection mechanism of Botrytis cinerea Pers. Neth. J. Plant Pathol. 95, Suppl. 1:53-62.

7. Elad, Y. 1988. Latent infections of Botrytis cinerea in rose flowers and combined chemical and physiological control of the disease. Crop Prot. 7:361-366.

8. Elad, Y. 1996. Mechanisms involved in the biological control of Botrytis cinerea incited diseases. Eur. J. Plant Pathol. 102:719-732.

9. Hu, X., Nazar, R. N., and Robb, J. 1993. Quantification of Verticillium biomass in wilt disease development. Physiol. Mol. Plant Pathol. 42:23-36.

10. Jackson, A. J., Walters, D. R., and Marshal, G. 1994. Evaluation of Penicillium chrysogenum and its antifungal extracts as potential biological control agents against method for quantifying mold in harvested wine grapes. Am. J. Enol. Vitic. 45:300-304.

17. Maude, R. B. 1963. Testing the viability of Septoria on celery seed. Plant Pathol. 12:1517.

18. Mercier, J., and Wilson, C. L. 1994. Colonization of apple wounds by naturally occurring microflora and introduced Candida oleophila and their effect on infection by Botrytis cinerea during storage. Bio. Control 4:138-144.

19. Meyer, U. M., and Dewey, F. M. Efficacy of different immunogens for raising monoclonal antibodies to Botrytis cinerea. Mycol. Res. In press.

20. Nicholson, P., Lees, A. K., Maurin, N., Parry, D. W., and Rezanoor, H. H. 1996. Development of a PCR assay to identify and quantify Microdochium nivale var. nivale and Microdochium nivale var. majus in wheat. Physiol. Mol. Plant Pathol. 48:257-271.

21. Oliver, R. P., Farman, M. L., Jones, J. D. G., and Hammond-Kosack, K. E. 1993. Use of fungal transformant expressing $\beta$-glucuronidase activity to detect infection and measure hyphal biomass in infected plant tissues. Mol. Plant-Microbe Interact. 6:521-525.

22. Ricker, R. W., Marois, J. J., Dlott, J. W., Bostock, R. M., and Morrison, J. C. 1991. Immunodetection and quantification of Botrytis cinerea on harvested wine grapes. Phytopathology 81:404-411.

23. Robb, J., Hu, X., Platt, H., and Nazar, R. 1994. PCR-based assays for the detection and quantification of Verticillium species in potato. Pages 83-90 in: Modern Assays for Plant Pathogenic Fungi: Identification, Detection and Quantification. A. Schots, F. M. Dewey, and R. P. Oliver, eds. CAB Int., Cambridge University, Cambridge.

24. Salinas, J., and Schots, A. 1994. Monoclonal antibodies-based immunofluorescence test for detection of conidia of Botrytis cinerea on cut flowers. Phytopathology 84:351-356.

25. Sanderson, P. G., and Spotts, R. A. 1995. Postharvest decay of winter pear and apple fruit caused by species of Penicillium. Phytopathology 85:103-110.

26. Spotts, R. A. 1986. Relationships between inoculum concentrations of three decay fungi and pear fruit decay. Plant Dis. 70:386-389.

27. Torrance, L. 1992. Serological methods to detect plant viruses: Production and use of monoclonal antibodies. Pages 7-33 in: Techniques for the Rapid Detection of Plant Pathogens. J. M. Duncan and L. Torrance, eds. Blackwell Scientific Publications, London. 